\title{
PRELIMINARY DEFINITIONS FOR THE SONOGRAPHIC FEATURES OF SYNOVITIS IN CHILDREN
}

\section{Authors}

Johannes Roth MD PhD, Viviana Ravagnani MD PhD, Marina Backhaus MD PhD, Peter Balint MD PhD, Alessandra Bruns MD MSc, George A Bruyn MD PhD, Paz Collado MD PhD, Lorenia De la Cruz MD, Severine Guillaume-Czitrom MD, Troels Herlin MD $\mathrm{PhD}$, Cristina Hernandez MD, Annamaria Iagnocco MD PhD, Sandrine Jousse-Joulin MD, Stefano Lanni MD, Vibke Lilleby MD PhD, Clara Malattia MD PhD, Silvia MagniManzoni MD PhD, Consuelo Modesto MD, Ana Narrodi MD, Juan-Carlos Nieto MD, Sarah Ohrndorf MD, Linda Rossi MD, Anne-Marit Selvaag MD PhD, Nanno Swen MD PhD, Tracy Ting MD MSc, Nikolay Tzaribachev MD, Patricia Vega-Fernandez MD, Jelena Vojinovic MD PhD, Daniel Windschall MD, Maria-Antonietta D’Agostino MD $\mathrm{PhD}$, Esperanza Naredo MD PhD for the OMERACT Ultrasound Group

Jelena Vojinovic has received speakers' honorara from Abbvie, Pfizer and Roche (less than $10000 \$$ each). The remaining authors declare no financial conflicts.

\section{Corresponding Author}

Johannes Roth, MD PhD FRCPC RhMSUS, Children's Hospital of Eastern Ontario, 401 Smyth Road, Ottawa, ON, K1H 8L1, Canada

Telephone: 001-613-737-7600, Fax: 001-613-738-4297, Email: jroth@,cheo.on.ca

\section{Key Words:}

Ultrasonography - Pediatric Rheumatology - Outcome Measures - Synovitis - Imaging

\section{Word count:}

\section{Abstract 244}

\section{Manuscript 3277}

This article has been accepted for publication and undergone full peer review but has not been through the copyediting, typesetting, pagination and proofreading process which may lead to differences between this version and the Version of Record. Please cite this article as an 'Accepted Article', doi: 10.1002/acr.23130 (C) 2016 American College of Rheumatology Received: Jul 09, 2016; Revised: Oct 04, 2016; Accepted: Oct 11, 2016 
Sonographic Definitions for Synovitis in Children

\section{ABSTRACT}

\section{Objectives}

Musculoskeletal ultrasonography (US) has the potential to be an important tool in the assessment of disease activity in childhood arthritides. To assess pathology, clear definitions for synovitis need to be developed first. The aim of this study was to develop and validate these definitions through an international consensus process.

\section{Methods}

The decision on which US techniques to use, the components to be included in the definitions as well as the final wording were developed by 31 ultrasound experts in a consensus process. A Likert scale of 1-5 with 1 indicating complete disagreement and 5 complete agreement was used. A minimum of $80 \%$ of the experts scoring 4 or 5 was required for final approval. The definitions were then validated on 120 standardized US images of the wrist, MCP and tibiotalar joints displaying various degrees of synovitis at various ages.

\section{Results}

B-Mode and Doppler should be used for assessing synovitis in children. A US definition of the various components (i.e. synovial hypertrophy, effusion and Doppler signal within the synovium) was developed. The definition was validated on still images with a median of $89 \%$ (range $80-100$ ) of participants scoring it as 4 or 5 on a Likert scale.

\section{Conclusions}

US definitions of synovitis and its elementary components covering the entire pediatric age range were successfully developed through a Delphi process and validated in a webbased still images exercise. These results provide the basis for the standardized US assessment of synovitis in clinical practice and research. 
Sonographic Definitions for Synovitis in Children

Significance and Innovations

Musculoskeletal Ultrasonography is an important tool for the clinical assessment and research in childhood arthritides

Precise definitions for synovitis on ultrasonography in children are an essential prerequisite for the reliable use of this technology in the pediatric age group

Ultrasonographic definitions for synovitis in children were developed and validated for the first time through an international consensus process
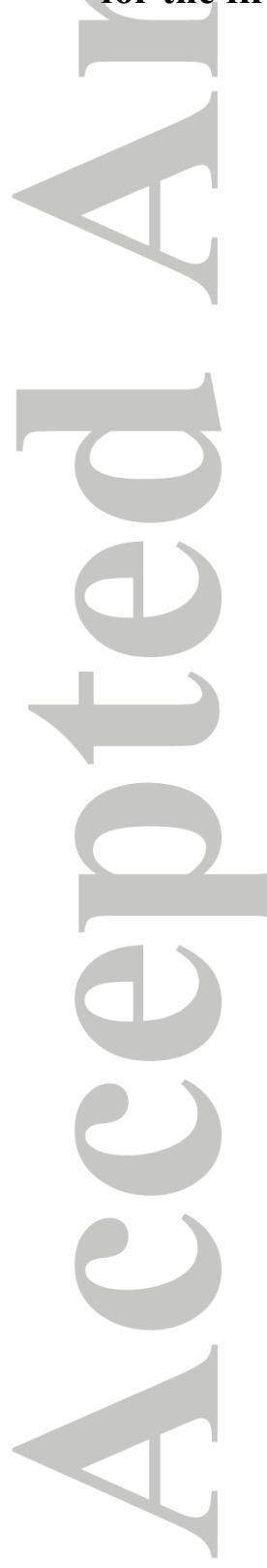

John Wiley $\stackrel{3}{\&}$ Sons, Inc. 
Sonographic Definitions for Synovitis in Children

\section{Introduction}

Musculoskeletal ultrasonography (US) has become an important outcome measurement tool in the assessment of inflammatory arthritis over the past decade (1-5). Although classification, treatment decisions and outcomes are generally based on the clinical examination only, it is now clear that US can add further information on the presence of a subclinical synovitis in a significant percentage of joints (6-9). The exact determination of the presence of disease activity may also be important in the determination of remission status and the decision to taper medication thereby preventing side effects from long-term use.

US is a particularly attractive imaging technique in pediatric rheumatology given its unique ability to be used in children of any age without sedation, to assess several joints at the same time and to differentiate all relevant structures including bone, cartilage and the various connective tissues $(2,11)$. This is especially important in the context of new treatments, which allow the induction of sustained remission for an increasing percentage of children but at the same time rely on precise assessments of disease activity for their effective use $(2,10)$.

Considering the widespread use of US in the management of inflammatory arthritis, especially rheumatoid arthritis, the need of improved standardization has emerged over the past decade for adult rheumatology. This has led to the development of consensus definitions for US-synovitis in adults as follows: "Synovial Fluid - Abnormal hypoechoic or anechoic (relative to subdermal fat, but sometimes may be isoechoic or hyperechoic) intraarticular material that is displaceable and compressible, but does not exhibit Doppler signal. Synovial Hypertrophy - Abnormal hypoechoic (relative to 
Sonographic Definitions for Synovitis in Children

subdermal fat, but sometimes may be isoechoic or hyperechoic) intraarticular tissue that is non-displaceable and poorly compressible and which may exhibit Doppler signal."(12).

The US detection of synovitis has also been validated with histology and MRI and the scanning technique standardized (13-15). These aspects have nevertheless only been partially addressed for pediatric patients $(2,16)$. In fact, very few publications have started to collect information on US in the pediatric population (16).

(5ta

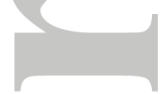

A systematic review concluded that the evidence basis for the use of US in pediatric rheumatology has not been established yet (16). At the same time, a recent survey emphasizes the great interest of pediatric rheumatologists in this technique (17). One of the unmet needs addressed by the review was the lack of US definitions of the components of the healthy joint, given the unique anatomy of the growing child.

Since then, the Outcomes Measure in Rheumatology (OMERACT) ultrasound group has published definitions for the sonographic appearance of the normal joint, emphasizing the variable degree of un-ossified hyaline cartilage in the epiphysis in addition to the portion of hyaline cartilage that constitutes the articular cartilage (11). Other aspects described for a normal pediatric joint include the growth plate, hyperechoic echoes representing vascular channels and the precise differentiation of the joint capsule from the synovial recess (11). Finally, recommendations for the standardized assessment of various joints have also been published (18).

The next step therefore was to develop precise definitions for US pathology at the joint level. This has been shown in adults to be essential for good inter-rater reliability $(1,12)$. Pathologic findings can relate to a multitude of structures including the synovial recess, 
Sonographic Definitions for Synovitis in Children

the tendon sheath, the paratenon, the enthesis as well as structural damage (i.e. erosions). All of these structures display specific pediatric characteristics and cannot be treated indiscriminately, but need their own specific process of definition and validation (1). The aim of this study therefore was to develop definitions for synovitis and of each elementary component (i.e. synovial thickening, synovial effusion and Doppler signal), both in B-Mode and Doppler-Mode, through a consensus process and to validate the applicability of these definitions using still images of synovitis of different joints and in different age-related groups.
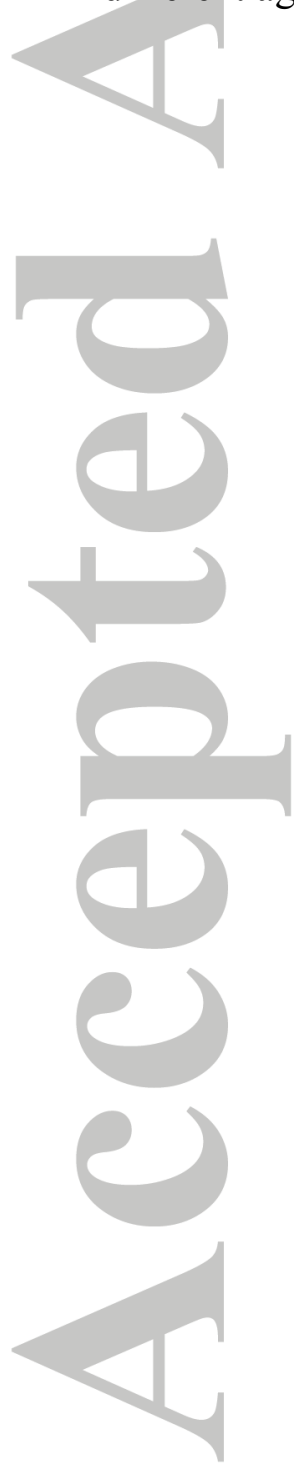

John Wiley ${ }^{6}$ s Sons, Inc.

This article is protected by copyright. All rights reserved. 
Sonographic Definitions for Synovitis in Children

\section{MATERIAL AND METHODS}

The definitions as well as their validation were developed in a two-step consensus process involving a panel of international experts on US in children (Figure 1) using a web survey.

In phase 1 of this web-based consensus process a group of 33 experts were invited to develop definitions for synovitis as seen on ultrasonography in children. All of these experts have extensive experience (5 to 15 years) in US including in children, with the majority being pediatric rheumatologists. All of them are part of the scientific validation of US including participation in the work of the OMERACT US group.

In order to agree on a term, a component or a complete definition, $\geq 80 \%$ of participants would need to reach $\geq 80 \%$ of agreement on a Likert scale from $1-5$. In practical terms this would mean that $\geq 80 \%$ of participants would score the respective term/definition/component as either 4 or 5 on the Likert scale. The scale was defined as:

1 strongly disagree, 2 disagree, 3 neutral, 4 agree and 5 strongly agree.

The goal of phase 2 was to validate the definitions by testing their applicability on ultrasound images representing various degrees of synovitis in various age groups. The same experts who had participated in the entire process of phase 1 were invited to submit images of variable degrees of synovitis at various ages and each of them was then asked

to assess the applicability of the synovitis definitions on each of the images using the same Likert scale as above.

Phase 1 - development of definitions for synovitis:

John Wiley ${ }^{7}$ \& Sons, Inc. 
Sonographic Definitions for Synovitis in Children

The phase 1 of the consensus process involved 6 rounds of scoring until agreement on a definition for synovitis was reached. The first round of phase 1 was dedicated to scoring the relevance of various ultrasound modalities in the assessment of synovitis. The aim was to identify the relevant joint structures and the terminology used to describe them with the idea to use the results of this first round to draft actual definitions. Specifically, the participants were asked to agree on whether the detection of synovitis on US should include B-Mode and Doppler and whether it would be essential that abnormalities should be detected with both modalities in order to confirm the presence of synovitis. In addition, the various structures within and around a joint were scored as per their relevance to be included in a definition of synovitis. This included the joint capsule as well as connective tissues like fat, but also the question whether synovial fluid detected alone, in case of the inability to clearly visualize the presence of a synovial thickening (for example for the lack of an acoustic window) should be endorsed. With regards to a thickened synovial membrane the participants were asked to score the term "hypertrophy" vs "hyperplasia" to be included in the definition. Finally, the ultrasound characteristics of the various structures were scored using terms describing the echogenicity (an-, hypo-, hyperechoic) as well as the physical properties (displaceable, compressible). The specific location of Doppler flow was addressed as well asking participants to score the presence of these signals in an intra-articular vs intra-synovial location.

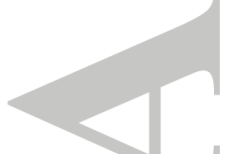

In preparation for the second round, complete definitions of synovitis were proposed by John Wiley $\stackrel{8}{\&}$ Sons, Inc. 
Sonographic Definitions for Synovitis in Children

the conveners of this project (EN and JR) using various combinations of the modalities, structures and characteristics that had been suggested in round 1 .

The third round was designed to clarify aspects, which did not reach consensus in the second round by providing separate statements instead of a full definition, and their relevance for the final development of the definitions.

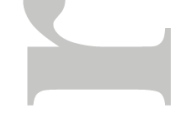

The fourth round was needed to further clarify terms for which the required agreement had not been reached and the further modified definitions were then scored in round 5.

In a sixth and final round a final version of the definition was circulated in order to harmonize the terminology used for synovitis and the elementary components with other projects within the OMERACT group.

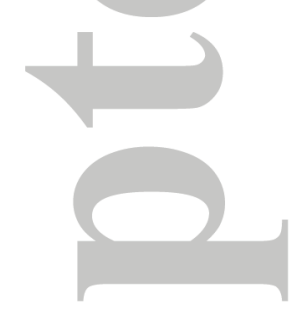

Phase 2 - Validation of the definitions on still images

Following the agreement on definitions all the participants were then invited to submit BMode and Doppler images of synovitis of the following joints: metacarpo-phalangeal (MCP), the wrist and tibiotalar joints. Separate images were submitted for the following 4 age groups: toddler and preschool age 2-4 years, young children age 5-8 years, preadolescent age 9-12 years and teenagers age 13-16 years (18). Participants were John Wiley 9 \& Sons, Inc. 
Sonographic Definitions for Synovitis in Children

asked to acquire the scans using standardized views, including longitudinal midline scans and a dorsal approach for MCP and wrist, as agreed in a previous exercise (18). The images also had to fulfill minimum quality criteria including a thin layer of gel at the top of the image, clear visibility of bone contours and correct size of the Doppler box, i.e. the Doppler box had to include the relevant joint structures and extend to the top of the image. In each age group we ensured representation of various degrees of synovitis. These degrees were determined by the participant submitting the image according to a recently published scoring system for the pediatric joint (19). One image representing each of the degrees of synovitis (0-3) was submitted and an additional image with an arbitrary grade was also added. For the knee joint only a single image each for B-mode and Doppler was submitted for every age group as the scoring system for this joint is slightly different (19). Only completely anonymized images were used and all participating centers did not require ethics approval for this web based exercise.

Again, participants were asked to score the applicability of the definitions on each of these images using the same Likert scale as in phase 1 with the same agreement threshold.

John Wiley 10 Sons, Inc.

This article is protected by copyright. All rights reserved. 
Sonographic Definitions for Synovitis in Children

\section{RESULTS}

\section{Phase 1}

In the first round of phase 1, 31 of the 33 experts who had been approached responded. The consensus from the expert group was to include both B-Mode and Doppler as ultrasound modalities that can be used to assess synovitis in children, but there was no agreement on whether both methods would have to be used in combination or could be used separately.

Instead, the experts commented on the need to clearly define each elementary component i.e. synovial thickening, synovial fluid and Doppler signal using both modalities separately as a first step.

In terms of the specific components, expert consensus suggested to focus on the synovium and the synovial recess as well as the intraarticular location. We also included both "synovial fluid" as well as "synovial hypertrophy/hyperplasia" (no agreement was reached for choosing one instead of the other) in the definition and use the terms "(non)displaceable" (84\% agreement) as well as "an- or hypoechoic" (93\% agreement) to characterize this finding. Seventy-one percent agreed that pathologic Doppler signal should be detected in an area of synovial hyperplasia/hypertrophy detected on B-mode. Finally, $77 \%$ agreed that physiologic Doppler signal might be seen in the intraarticular area even in absence of synovial pathology, but only $48 \%$ at that stage agreed that physiologic Doppler signal in the intra-synovial area should also be mentioned in the synovitis definition. Main concerns related to the question of how to define these signals. 
Sonographic Definitions for Synovitis in Children

In the second round, 30 out of the 31 participants of the first round responded. Complete suggestions for definitions that were developed based on round 1 were proposed but none of the various options reached the required consensus. Synovial fluid and synovial hypertrophy were included in a unique definition of synovitis emphasizing the need for Doppler signals to be within an area of synovial hypertrophy. The definition also acknowledged the possibility of physiologic Doppler signals inside the joint as well as within the synovial recess and included the terms an- or hypoechoic and (non)displaceable for further characterization, including the quality of the machine.

In the third round the definition was divided again into separate statements in order to identify components that would reach full agreement and others that would require further modification. Agreement ( $86 \%$ each) was reached for the following statements: "Depending on the joint, synovitis can be diagnosed on the basis of B-mode abnormalities and in the absence of Doppler signals". "For the definition of synovial inflammation detected by Doppler mode, the Doppler signal should be shown within an area of synovial hypertrophy". No final agreement was reached on the characterization of the synovial fluid and hypertrophy/hyperplasia with regards to its physical properties ("displaceable", "compressible" etc.), the echogenicity and also other terms to characterize it like "abnormal" vs. "increased".

In the fourth round various options for these remaining aspects were therefore given and 80-97\% agreement was reached to include the following statements in the definition: "Bmode findings can include synovial effusion and/or synovial hypertrophy". "Synovial 
Sonographic Definitions for Synovitis in Children

effusion should be defined as abnormal intraarticular fluid, characterized as an- or hypoechoic and displaceable". "Synovial hypertrophy should be defined as nondisplaceable, intraarticular and hypoechoic material". "For pathologic Doppler signals the term abnormal Doppler signals should be used".

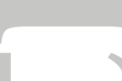

In the fifth round a complete version for the definition was provided for final agreement.

(n)

In the sixth round the final version of the definitions obtained approval. This final version is shown in figure 2 and sample ultrasound images illustrating the various aspects of the definition are provided as Figures 3 and 4.

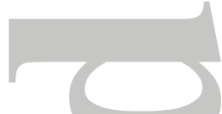

\section{Phase 2}

The applicability of the final definition was scored on a total of 120 images representing various grades of synovitis within various age groups and representing female and male patients by 19 experts. An 80-100\% (median $89 \%$, range 80-100) agreement of grade 4 or 5 on the Likert scale was reached in all but one images, the one image was a Doppler image of the MCP joint in the 9-12 age group reaching $74 \%$.

John Wiley 13 Sons, Inc. 
Sonographic Definitions for Synovitis in Children

\section{DISCUSSION}

Definitions for the US appearance of synovitis in children were successfully developed through a consensus process and validated on still images. This represents another important step for a more reliable use of US in children following the definition of findings of the normal joint (11) and the publication of standard views to assess various joints (18). At the same time, it is clear that these definitions should be validated further in a patient-based practical exercise. In addition, the same standardization process should be applied to other relevant structures including tendons and tendon sheaths, entheses and structural lesions like erosions $(1,2,11,16,20)$. Previous work done by the OMERACT ultrasound group in adults has shown that even assessments of single types of joints can be challenging and might need a relatively lengthy development process of precise definitions in order to achieve good intra- and interrater reliability of this method (1). A simple adaptation for pediatrics of standardization and validation that has been done in adults is not possible mainly because of the significant changes related to cartilage maturation, growth and blood flow in various areas of the joint (11).

There are several important findings of this study relating to the use of US:

i) As in adults, the definition and the assessment of synovitis by US require the use of both B-mode and Doppler mode. Given the complex anatomy of many joints it is nevertheless extremely important to clearly identify the synovial recess on B-Mode and differentiate this recess from other connective tissue, which might be intraarticular but extra-synovial (11) and can mimic the presence of an abnormal synovial thickening/effusion. This is especially important for the correct interpretation of Doppler signals. Children will show a variable degree of physiologic blood flow within the joint 
Sonographic Definitions for Synovitis in Children

and this should not be confused with pathologic Doppler signals as a sign of synovitis. Only Doppler signals within an area of synovial hypertrophy will clearly be suggestive of increased blood flow as part of the inflammatory process. This clear emphasis on the precise intrasynovial and not just intraarticular location of the Doppler signals represents an evolution of and differentiation from the existing definition in adults (12). It is especially important in the pediatric context with the significant presence of intraarticular but physiologic blood flow that can be depicted with Doppler ultrasonography. However, the technical limitations affecting the sensitivity of Doppler especially for large joints where the joint recess is located relatively deep (6) should be taken into account.

ii) Our definition of an US-detected synovitis in children reflects the different anatomy of the joints, by allowing the diagnosis of synovitis based on B-mode only (i.e. presence of synovial thickening and/or effusion, without Doppler signal). It also emphasizes the need to define the use of this technology in a more detailed way with variations of its use according to the different joints. A "one-size-fits-all" approach is therefore not possible and the limitations of the technique need to be discussed clearly in order to ensure its appropriate use, and to take into account the different quality of the Doppler mode according to the type of the US equipment. (22).

iii) Finally, the possibility of the presence of physiologic Doppler signal in any area of the joint including the synovial recess (18) requires the sonographer to recognize and distinguish them from truly pathologic findings. For instance, feeding vessels can traverse the synovial recess but can be easily recognized by their direct trajectory into the bone/cartilage. Interesting aspects that were discussed during the consensus process but need to be clarified in future longitudinal studies are the hyperemia and therefore increased visibility of feeding vessels in states of inflammation as well as peri-synovial 
Sonographic Definitions for Synovitis in Children

and even periarticular hyperemia that might be an important sign of inflammatory activity, but hasn't been studied systematically yet.

Two main Doppler techniques are being used in US at this point: Power Doppler and Color Doppler (22). Whereas the sensitivity of Power Doppler was considered superior in the detection of low velocity blood-flow as seen in the inflamed synovium in the past, this is no longer universally true. Instead the question of which technique should be used to obtain maximum sensitivity very much depends on the ultrasound machine and the optimization of settings (22). Our definition therefore includes power and color Doppler.

We have not validated our definition on any possible joint, but have covered three frequently affected joints of the upper and lower extremity as well as representing large and small joints. The three joints were also chosen based on the fact that some preliminary scoring suggestions for the degree of synovitis in the pediatric setting were available (19). This was important as we wanted to ensure an appropriate range of degrees of synovitis to test the applicability of our definitions. The number of 120 images was found to be the most appropriate as it covered the various degrees of synovitis and allowed an additional random image each.

Some of the terms used in our definitions led to fairly extensive discussions. Especially the characterization of synovial thickening as "synovial hyperplasia" vs. "synovial hypertrophy" was discussed in detail. While from a histologic perspective the term "hyperplasia" would be more appropriate the reality of the widespread use of the term "hypertrophy" led to a consensus to use this latter term in our definitions in order to ensure universal acceptance. 
Sonographic Definitions for Synovitis in Children

No validation of our definitions using a comparison method like MRI was done for two reasons: a) the aim of this study was to define characteristics of synovitis that can be assessed on ultrasonography and not to validate the detection of synovitis itself. This has been done in several studies in adults already (1), but it will also be important to do this at some stage in children - b) the use of other imaging technologies like MRI is currently being standardized and evaluated precluding the use of this technology as a gold standard in pediatrics for comparison purposes at the current time $(2,3)$.

The definitions presented in this study are feasible and reliable to apply. They will support US in the routine clinical assessment and be used as an outcome measure in research.

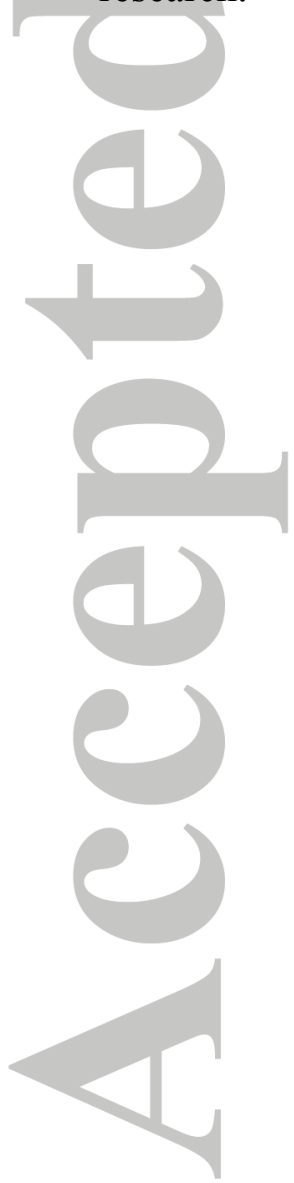

John Wiley \& Sons, Inc. 
Sonographic Definitions for Synovitis in Children

\section{Acknowledgements:}

This work was supported by the Canadian Rheumatology Ultrasound Society, a non-forprofit organization.

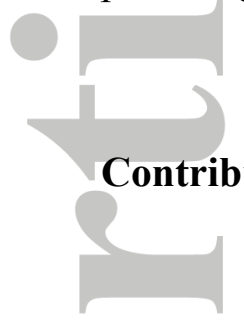

All listed authors have had substantial contributions in the acquisition, analysis, and interpretation of data for the work; they were involved in revising it critically and give final approval for the version to be published. All authors agree to be accountable for all aspects of the work in ensuring that questions related to the accuracy or integrity of any part of the work are appropriately investigated and resolved.

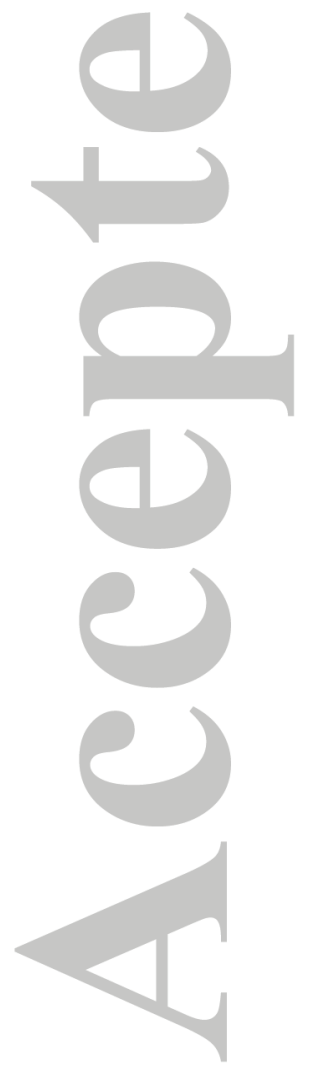

John Wiley 18 Sons, Inc.

This article is protected by copyright. All rights reserved. 
Sonographic Definitions for Synovitis in Children

\section{REFERENCES}

1) Naredo E, Wakefield RJ, Iagnocco A, Terslev L, Filippucci E, Gandjbakhch F et al. The OMERACT ultrasound task force--status and perspectives J Rheumatol. 2011 Sep;38(9):2063-7

2) Lanni S, Wood M, Ravelli A, Magni Manzoni S, Emery P, Wakefield RJ. Towards a role of ultrasound in children with juvenile idiopathic arthritis. Rheumatology (Oxford). 2013 Mar;52(3):413-20

3) Damasio MB, Malattia C, Martini A, Toma P. Synovial and inflammatory diseases in childhood: role of new imaging modalities in the assessment of patients with juvenile idiopathic arthritis. Pediatr Radiol 2010 Jun;40(6):985-98.

4) Backhaus M, Kamradt T, Sandrock D, Loreck D, Fritz J, Wolf KJ et al. Arthritis of the finger joints: a comprehensive approach comparing conventional radiography, scintigraphy, ultrasound, and contrast-enhanced magnetic resonance imaging.

Arthritis Rheum. 1999; 42:1232-45

5) Brown AK, Conaghan PG, Karim Z, Quinn MA, Ikeda K, Peterfy CG et al. An explanation for the apparent dissociation between the clinical remission and continued structural deterioration in rheumatoid arthritis.

Arthritis Rheum 2008; 58: 2958-67.

6) Rebollo-Polo M, Koujok K, Weisser C, Jurencak R, Bruns A, Roth J.

Ultrasound findings on patients with juvenile idiopathic arthritis in clinical remission. Arthritis Care Res (Hoboken). 2011 Jul;63(7):1013-9

7) Magni-Manzoni S, Epis O, Ravelli A, Klersy C, Veisconti C, Lanni S et al. Comparison of clinical versus ultrasound-determined synovitis in juvenile idiopathic arthritis.Arthritis Rheum. 2009 Nov 15;61(11):1497-504.

8) Collado P1, Gamir ML, López-Robledillo JC, Merino R, Modesto C, Monteagudo I.H. Detection of synovitis by ultrasonography in clinically inactive juvenile idiopathic arthritis on and off medication. Clin Exp Rheumatol. 2014 JulAug;32(4):597-603.

9) Wakefield RJ, Green MJ, Marzo-Ortega H, Conaghan PG, Gibbon WW, McGonagle D et al. Should oligoarthritis be reclassified? Ultrasound reveals a high prevalence of subclinical disease. Ann Rheum Dis. 2004 Apr;63(4):3825 .

10)Guzman J, Oen K, Huber AM, Watanabe Duffy K, Boire G, Shiff N et al.; ReACCh-Out investigators. The risk and nature of flares in juvenile idiopathic 
Sonographic Definitions for Synovitis in Children

arthritis: results from the ReACCh-Out cohort. Ann Rheum Dis. 2015 May 18. pii: annrheumdis-2014-207164. doi: 10.1136/annrheumdis-2014-207164. [Epub ahead of print]

11) Roth J, Jousse-Joulin S, Magni-Manzoni S, Narrodi A, Tzaribachev N, Iagnocco A et al. OMERACT Definitions for the Sonographic Features of the Normal Pediatric Joint. Arthritis Care Res (Hoboken). 2015 Jan;67(1):136-42.

12)Wakefield RJ, Balint PV, Szkudlarek M, Filippucci E, Backhaus M, D'Agostino MA et al.; OMERACT 7 Special Interest Group. Musculoskeletal ultrasound including definitions for ultrasonographic pathology. J Rheumatol. 2005 Dec;32:2485-7.

13)Walther M, Harms H, Krenn V, Radke S, Faehndrich TP, Gohlke F. Correlation of power Doppler sonography with vascularity of the synovial tissue of the knee joint in patients with osteoarthritis and rheumatoid arthritis. Arthritis Rheum 2001 Feb;44(2):331-8.

14)Schmidt WA, Schmidt H, Schicke B, Gromnica-Ihle E. Standard reference values for musculoskeletal ultrasonography. Ann Rheum Dis. 2004 Aug;63(8):988-94

15)Naredo E, Batlle-Gualda E, García-Vivar ML, García-Aparicio AM, FernándezSueiro JL, Fernández-Prada M et al.; Ultrasound Group of the Spanish Society of Rheumatology. Power Doppler ultrasonography assessment of entheses in spondyloarthropathies: response to therapy of entheseal abnormalities. J Rheumatol. 2010 Oct;37(10):2110-7

16)Collado P, Jousse-Joulin S, Alcalde M, Naredo E, D'Agostino MA. Is ultrasound a validated imaging tool for the diagnosis and management of synovitis in juvenile idiopathic arthritis? A systematic literature review. Arthritis Care Res (Hoboken). 2012 Jul;64(7):1011-9

17)Magni-Manzoni S, Collado $P$, Jouse Joulin S, D’Agostino MA, Naredo E, Muratore $\mathrm{V}$ et al. Current state of musculoskeletal ultrasound in pediatric rheumatology practice: results of a survey among the international pediatric rheumatology networks. Rheumatology (Oxford). 2014 Mar;53(3):491-6

18)Collado P, Vojinovic J, Nieto JC, Windschall D, Magni-Manzoni S, Bruyn GA, et al.; OMERACT Ultrasound Pediatric Group. Toward Standardized Musculoskeletal Ultrasound in Pediatric Rheumatology: Normal Age-Related Ultrasound Findings. Arthritis Care Res (Hoboken). 2016 Mar;68(3):348-56.

19) Collado P, Naredo E, Calvo C, Gamir ML, Calvo I, García ML et al. ECO-JIA Study Group. Reduced joint assessment vs comprehensive assessment for 
Sonographic Definitions for Synovitis in Children

ultrasound detection of synovitis in juvenile idiopathic arthritis. Rheumatology (Oxford). 2013 Aug;52(8):1477-84

20)Grechenig W, Mayr JM, Peicha G, Hammerl R, Schatz B, Grechenig S. Sonoanatomy of the Achilles tendon insertion in children. J Clin Ultrasound 2004 Sep;32(7):338-43.

21)Magni-Manzoni S, Scirè CA, Ravelli A, Klersy C, Rossi S, Muratore V et al. Ultrasound-detected synovial abnormalities are frequent in clinically inactive juvenile idiopathic arthritis, but do not predict a flare of synovitis. Ann Rheum Dis. 2013 Feb;72(2):223-8.

22)Torp-Pedersen S, Christensen R, Szkudlarek M, Ellegaard K, D'Agostino MA, Iagnocco A et al. Power and color Doppler ultrasound settings for inflammatory flow: impact on scoring of disease activity in patients with rheumatoid arthritis.

Arthritis Rheumatol. 2015 Feb;67(2):386-95.

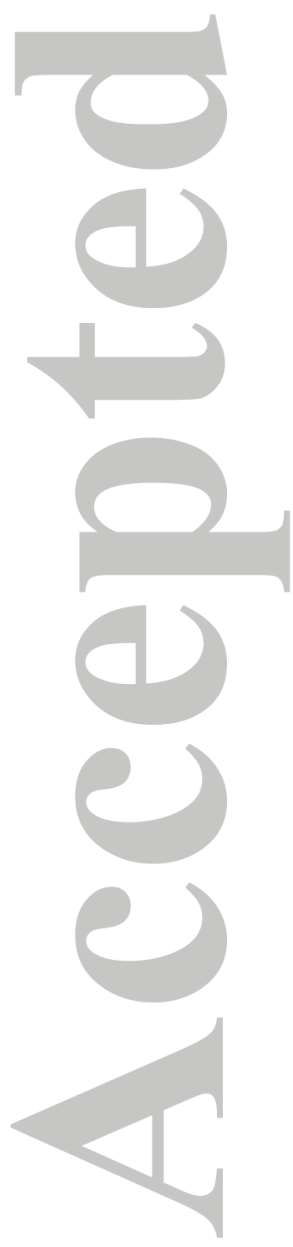

John Wiley \& Sons, Inc. 
Sonographic Definitions for Synovitis in Children

\section{Figure 1}

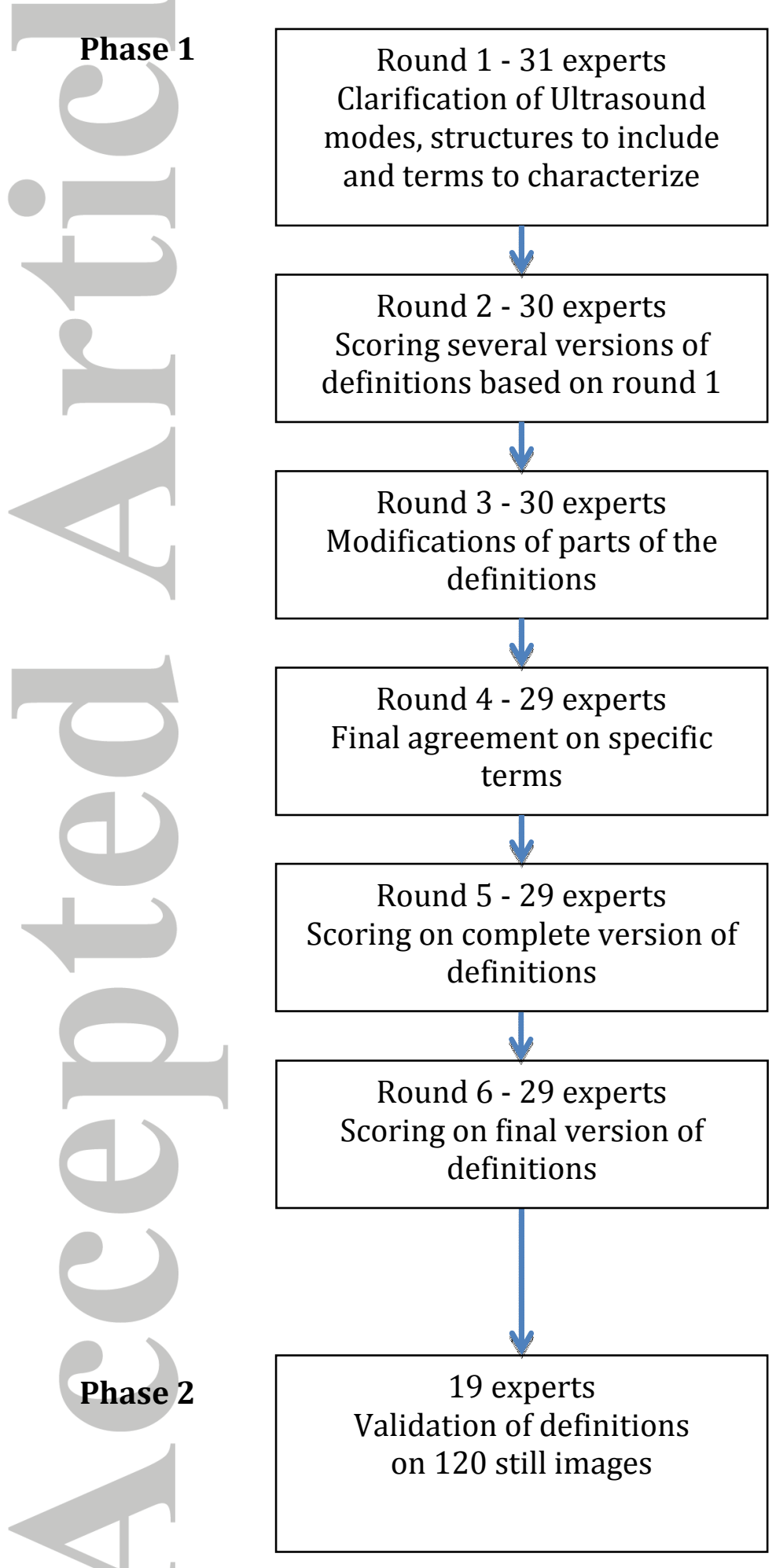

Figure Legend 1

John Wiley \& Sons, Inc.

This article is protected by copyright. All rights reserved. 
Sonographic Definitions for Synovitis in Children

Workflow outlining the consensus process (phase 1) to develop the definitions as well as the validation on still images (phase 2).

\section{Figure 2 - Final version for the Definition for Synovitis on ultrasonography in children}

Overarching principle: Synovitis detection by US in children includes the assessment of B-mode and Doppler mode (color or power Doppler) findings.

Synovitis can be detected on the basis of B-mode findings alone. Synovitis cannot be detected based on color/power Doppler findings alone.

B mode findings include synovial effusion and synovial hypertrophy.

Synovial effusion is defined as an abnormal, intraarticular, anechoic or hypoechoic material that is displaceable.

Synovial hypertrophy is defined as an abnormal, intraarticular, hypoechoic material that is non-displaceable.

Color/power Doppler signals must be detected within synovial hypertrophy to be considered as a sign of synovitis. 
Sonographic Definitions for Synovitis in Children

Figure 3 - Intraarticular Doppler signals in the wrist

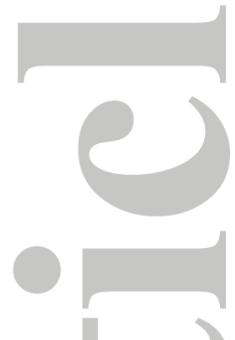

Figure 4 - Illustration of the various components of the synovitis definition
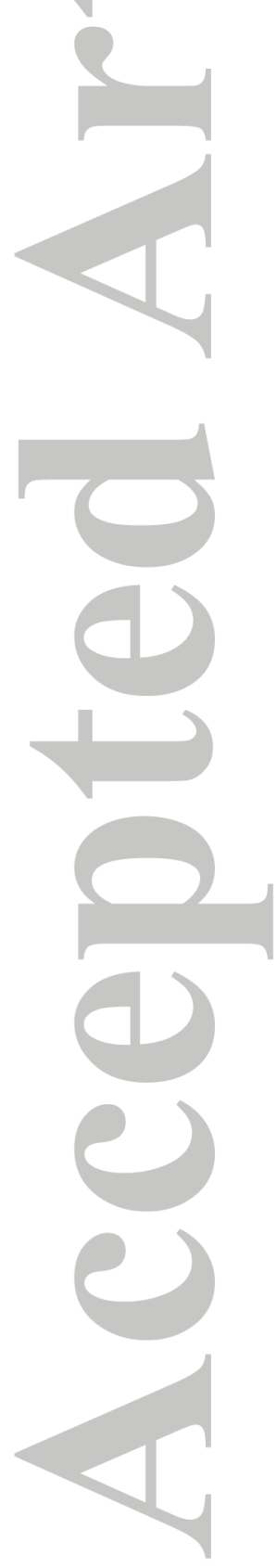

John Wiley \& Sons, Inc.

This article is protected by copyright. All rights reserved. 


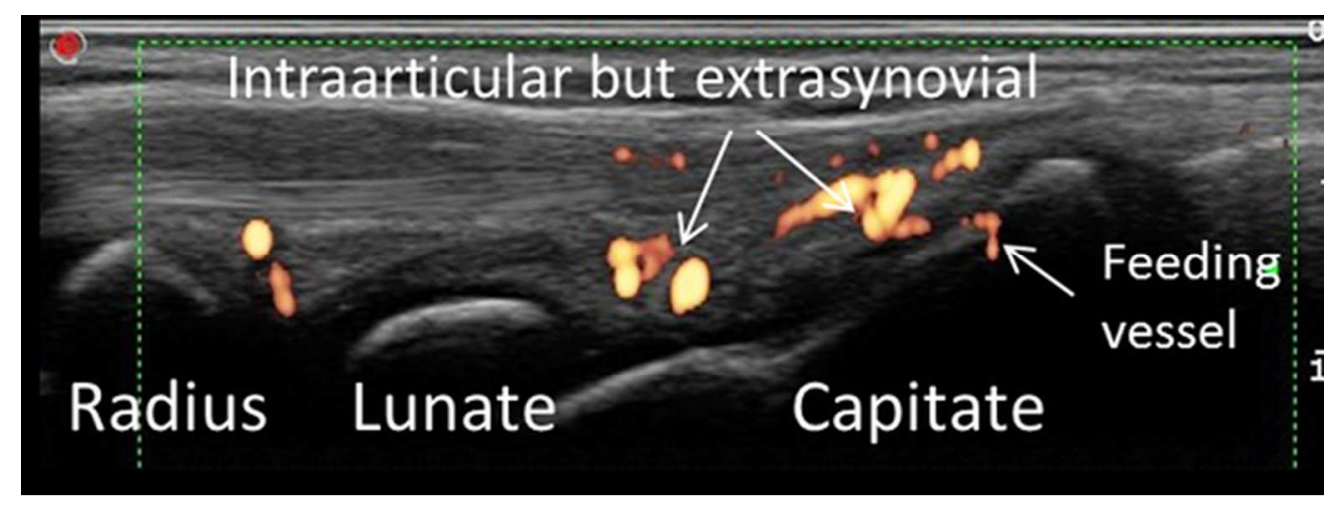

In this longitudinal midline image of the wrist of a 11 year old child Doppler signals are shown in an intraarticular but extrasynovial location including a feeding vessel

Figure 3 - Intraarticular Do

$86 \times 32 \mathrm{~mm}(300 \times 300 \mathrm{DPI})$

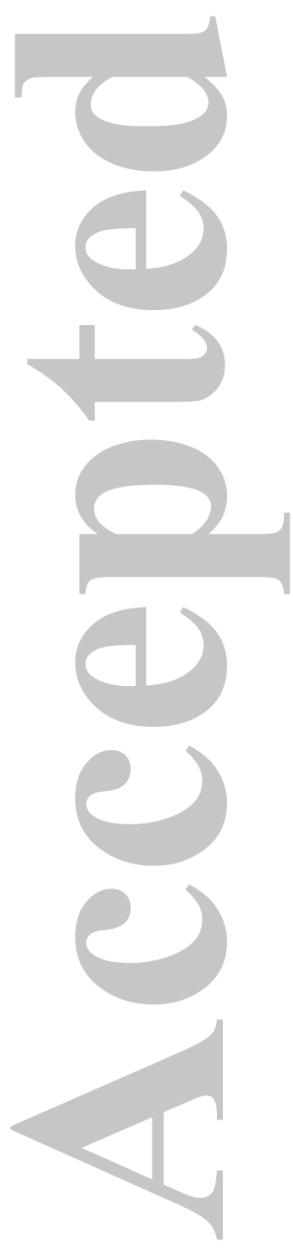

John Wiley \& Sons, Inc.

This article is protected by copyright. All rights reserved. 


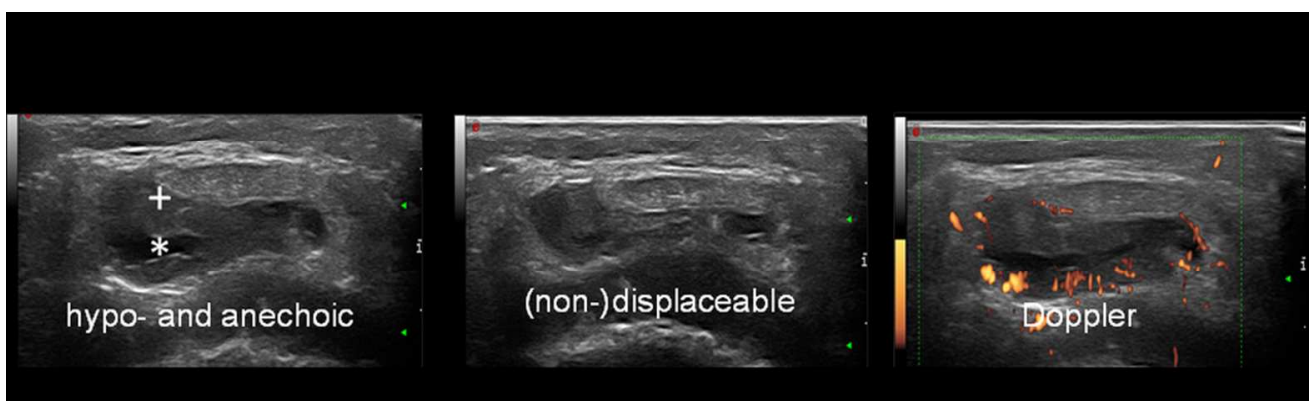

Intrasynovial Doppler signals as well as hypo- and anechoic components of synovitis and physical properties as shown in a deep infrapatellar bursa in transverse view, +=Synovium, * =Synovial Fluid.

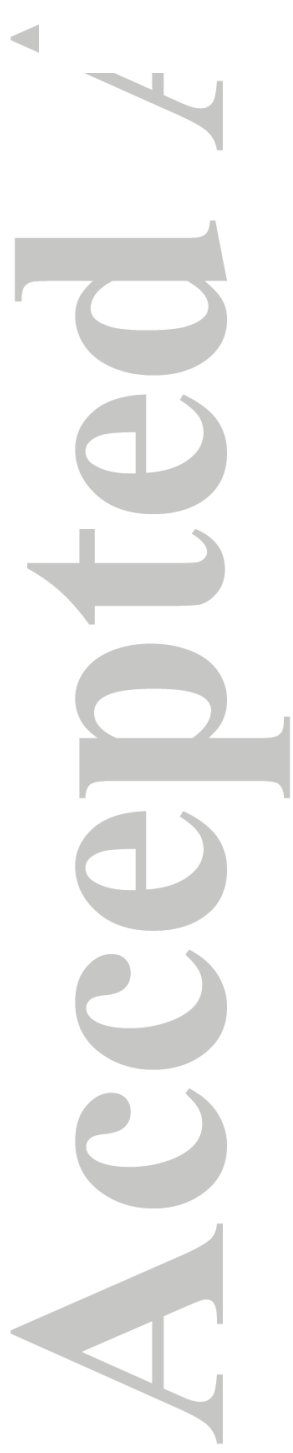

Figure 4 - Illustration of $\mathrm{t}$

$86 \times 25 \mathrm{~mm}(300 \times 300 \mathrm{DPI})$

John Wiley \& Sons, Inc.

This article is protected by copyright. All rights reserved. 